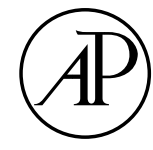

ACADEMIC PRESS

\section{Brain

\title{
Do orthographic cues aid language recognition? A laterality study with French-English bilinguals
}

\author{
Jyotsna Vaid* and Cheryl Frenck-Mestre \\ Texas A \& M University, College Station, Texas 77843-4235, USA
}

CNRS, Laboratoire Parole et Langage, University of Provence, Aix-en-Provence, France

Accepted 6 November 2001

\begin{abstract}
Sixteen French-English late bilinguals performed a speeded language recognition task on lateralized words that were either marked or unmarked for language on the basis of digram frequency. Response latencies were faster to orthographically marked than unmarked words, particularly in the second language (English). Furthermore, L2 marked words were responded to faster than L1 marked words. These effects were especially prominent for words presented in the left visual field. It is suggested that subjects made use of different strategies in performing the task of language recognition task, with a perceptual search strategy deployed to identify orthographically marked words, resulting in an L2 advantage for such words, and a lexical search strategy deployed for unmarked words, resulting in an L1 advantage for such words. () 2002 Elsevier Science (USA). All rights reserved.
\end{abstract}

Keywords: Language recognition; Digram; Orthographic cues; Visual half-field; Late bilinguals

\section{Introduction}

Word recognition in monolinguals entails an analysis of the appearance, sound, meaning, and grammar of the verbal input. For bilinguals, an additional level of analysis may be performed, namely, identifying the language of the input. Knowing the language of the input may facilitate the comprehension process, allowing bilinguals to selectively activate appropriate lexical candidates and semantic and syntactic aspects of the language in use (even if those of the other language are not entirely deactivated). Since languages differ on a variety of levels-prosodic, lexical, orthographic, and semantic/syntactic - the task of language assignment is usually quite effortless given the redundancy of cues normally available in discourse. Yet this very redundancy makes it difficult to establish which of these potential sources of information are actually used by bilinguals or whether all are used equally in making

\footnotetext{
${ }^{*}$ Corresponding author. Fax: +979-845-4727.

E-mail address: jxv@psyc.tamu.edu (J. Vaid).
} 
language assignments. To study the relative effectiveness of different sources of information signaling language of input would require isolating the different types of cues possible, thereby eliminating the redundancy that is normally present in the bilingual's sociolinguistic environment. Under isolated conditions, the role of specific cues may then be studied more directly.

Of interest in the present research was the role of surface cues signaling language of visually presented words in the bilingual's two languages. For language pairs that have differing writing systems, such as Arabic and French, script itself is sufficient for language assignment. But what is the role of orthography for languages in which words share a common writing system, such as English and French? Presumably orthography, at least in a global sense, would play less salient a role in language identification for languages that share a common writing system than for languages that do not. On the other hand, perhaps for languages that share a common orthography bilinguals turn to more subtle orthographic indicators of language such as, for example, the relative frequency of specific letter sequences in each of their languages. In the absence of other cues, might this orthographic cue aid in language identification? This was one of the questions addressed in the present research. Specifically, we were interested in establishing whether bilinguals would be faster in recognizing the language of a word if its digram frequency marks it as being more likely to be in one language than in the other, compared to the situation where the digram frequencies are equally high in both languages, rendering this variable uninformative for language assignment.

The evidence from psycholinguistic studies of bilingual lexical access is somewhat equivocal as concerns the role of orthographic cues in the language recognition process. It has been claimed that words with language-specific orthography enable "language-specific access," such that only candidates from one language (that compatible with the specific orthography) should be activated when this type of word is presented in a lexical decision task (Grainger \& Beauvillain, 1987). This conclusion has been called into question, however (cf. Thomas \& Allport, 2000; Von Studnitz \& Green, 1997). While bilinguals are most certainly able to benefit from the presence of orthographic cues, as shown by faster recognition of orthographically marked words, it is not at all clear that they specifically access only the "pertinent" lexicon when identifying this type of word (Thomas \& Allport, 2000).

In addition, we were interested in exploring whether sensitivity to orthographic marking of language would interact with bilinguals' relative proficiency in the two languages. When the task does not specifically require language identification, it appears that bilinguals are less efficient at extracting orthographic cues from words presented in their nondominant than dominant language (Favreau, Komoda, \& Segalowitz, 1980). Moreover, a certain level of experience with the L2 is necessary before bilinguals efficiently extract orthographic cues from second-language stimuli (Frenck-Mestre, 1993). When the task is specifically to identify the language of the stimulus words, however, it may well be that bilinguals (and late bilinguals, in particular) will be more prone to relying on orthographic cues to identify second than first language words. A longer history of reading words in L1 relative to L2 in late bilinguals should arguably provide additional cues besides that of digram frequency in determining language assignment for L1 words. For words in the second language, by contrast, which presumably do not have a comparable network of associations, the task of language assignment could effectively be performed by a perceptual search strategy, looking for such bottom up cues as are provided by digram frequency in the visual modality. Indeed, there are some hints in the literature that late bilinguals consistently make use of surface level cues when the task permits their use, as in tasks such as language recognition of auditorily presented 
words (Genesee et al., 1978) or rhyme judgments (Vaid, 1984, 1987). In these studies, the performance of late bilinguals was faster than that of monolinguals or early bilinguals, consistent with the view from previous bilingual memory research that late bilinguals are more likely to keep their two languages separate in processing and may, thus, have developed a particular sensitivity to cues marking language of input (Genesee et al., 1978; Vaid, 1984). Although the present research was not designed to compare early and late bilinguals, we hypothesized that the bilinguals in our study (all of whom happened to be late bilinguals) would pick up on the cues to language provided by digram frequency in performing the language identification task, particularly for L2 words. Thus, we expected that they would show faster L2 than L1 identification latencies for words containing orthographically marked information, all other things being equal.

A final variable of interest in the present study was the relative role of the right vs left hemisphere in sensitivity to orthographic information. Previous research with brain-intact individuals and commissurotomized patients suggests that both cerebral hemispheres contribute to language processing but that their contribution differs depending on the processing demands of the task. Findings from word pair comparisons with monolingual and bilingual subjects suggest that the right-hemisphere is particularly sensitive to surface level variation of words (e.g., rhyme judgments), whether in the visual or auditory modality (e.g., Vaid, 1984, 1987). A language recognition task has been examined in three previous bilingual laterality studies. Two used evoked potential recordings with monaurally presented words and obtained a right-hemisphere superiority on this task (Genesee et al., 1978; Kotik, 1989). A third, with Spanish-English bilinguals, used tachistoscopically presented words and found no overall hemifield asymmetries in speeded language identification (Vaid \& Frenck-Mestre, 1990). However, in this latter study, orthographic information was not systematically examined as a cue for language identification. The present study thus represents the first attempt to examine whether orthographic marking of language, as signaled by digram frequency, would be more reliably used by bilinguals for words presented to the left than to the right visual field.

In summary, the present research was designed to explore the influence of language status (first vs second), orthographic markedness (marked vs unmarked), and side of presentation (left vs right hemifield) in speeded classification of the language of visually presented single words.

\section{Method}

Participants. Sixteen French-English late bilingual adults, all right-handed and with normal vision, and including an equal number of men and women, participated in the study. All were native speakers of French and had learned English after the age of 12. At the time of testing, all were enrolled as graduate or postdoctoral students at Texas A \& M University, and had been living in the United States for a period ranging from 2 to 6 years. Based on their own self-assessment and on spoken interactions in both languages with one of the experimenters, subjects were judged to be moderately to highly fluent in their two languages.

Materials and procedure. The stimuli consisted of 64 medium- to high-frequency words ranging in length from four to seven letters, with half in English and half in French. Per language, half of the words contained digrams that were frequent in only one language (e.g., OEUF for French, or KICK for English); we refer to these as orthographically marked stimuli. The remaining had high digram frequencies in both languages (e.g., PONT and DROP) and were thus considered orthographically 
unmarked. Digram frequencies for French and for English were obtained by consulting Veronis (1986) and Carterrette and Jones (1974), respectively. Frequency norms were consulted in each language (Kucera \& Francis, 1967; Tresor de la Langue Francaise, 1971). Two lists were created, with half of the stimulus materials per list. This allowed the complete counterbalancing of stimuli across visual fields. In each list, there were four sets of eight words, representing two levels each of language and markedness, for a total of 64 stimuli (see Appendix A).

The stimulus words were prepared from black uppercase Helvetica Letraset letters and were positioned horizontally on white cards at a visual angle of 2 degrees to the left or right of center. The cards were presented individually on a Gerbrands threechannel tachistoscope for an exposure duration of $100 \mathrm{~ms}$, at a viewing distance of $57 \mathrm{~cm}$. Each stimulus was presented once, preceded by a central fixation symbol. Subjects were shown the 64 stimuli (half in each language and, within each language, half in each visual field) in a different random order. The experimenter administering the experiment was a fluent bilingual and instructions were provided in both languages. Subjects were to identify as quickly as possible whether the stimulus was a French or an English word. Responses were signaled by pressing one key for French and another for English with the right index finger. The particular keys (left and right) used for each language were counterbalanced across subjects. The intertrial interval was about $5 \mathrm{~s}$. Response latencies were recorded using a millisecond timer that was triggered by the onset of the stimulus and deactivated by pressing the response key. Trials on which errors occurred were noted and were repeated at the end of the dataset so that only latencies to correct responses were entered into the analysis.

\section{Results}

A 2 (Visual field) $\times 2$ (Language) by 2 (Markedness) analysis of variance was performed on the mean response times by subjects and by items. All observations that exceeded a cut-off value of $2500 \mathrm{~ms}$ were trimmed to that value (this affected less than $2 \%$ of the data). Table 1 presents a summary of the mean response latencies for all conditions.

There was no main effect of Language or of Visual field. Markedness approached significance $\left[F_{\mathrm{i}}(1,56)=2.72, p<.10 ; F_{\mathrm{s}}(1,15)=3.24, p<.09\right]$, with responses tending to be faster to words that contained language-specific digrams (e.g., OEUF and KICK) than to words containing digrams that were equally frequent in both languages (e.g., PONT and DROP). This effect was qualified by a significant Markedness by Language interaction $\left[F_{\mathrm{i}}(1,56)=4.6, p<.04 ; F_{\mathrm{s}}(1,15)=6.37\right.$, $p<.02]$. The interaction effect showed that orthographic markedness accelerated language identification only for words in English, the second language of subjects (responses were 1208 vs $1308 \mathrm{~ms}$ for marked and unmarked words, respectively). For words in French, the native language, marked items were not significantly faster

Table 1

Mean response latencies (and standard deviations) for language classification as a function of stimulus language, markedness, and visual hemifield

\begin{tabular}{|c|c|c|c|c|}
\hline & \multicolumn{2}{|c|}{ Left visual field } & \multicolumn{2}{|c|}{ Right visual field } \\
\hline & Marked & Unmarked & Marked & Unmarked \\
\hline French & $1295(506)$ & $1242(531)$ & $1262(508)$ & $1289(538)$ \\
\hline English & $1181(501)$ & 1322 (537) & 1235 (519) & $1295(521)$ \\
\hline
\end{tabular}


than unmarked ones (1278 vs $1266 \mathrm{~ms}$, respectively). Moreover, for marked words (e.g., KICK and OEUF), subjects' responses were significantly faster in English than in French; for unmarked words (e.g., PONT and DROP) there was a nonsignificant tendency for French words to be faster than English ones.

These effects were further qualified by a near significant higher order interaction of Markedness, Language, and Visual field $\left[F_{\mathrm{i}}(1,56)=2.33, p<.13, F_{\mathrm{S}}(1,15)=\right.$ 4.13, $p<.06]$. The three-way interaction indicated that the above pattern essentially obtained in the left visual field. Post hoc comparisons showed that the interaction between Markedness and Language was highly significant in the left visual field $\left[F_{\mathrm{S}}(1,15)=9.16, p<.01\right]$ but was not significant in the right visual field $\left[F_{\mathrm{S}}<1\right]$. Breakdown of the left visual field interaction means revealed the following: French words showed no effect of markedness (1295 vs $1242 \mathrm{~ms}$ for marked vs unmarked), whereas, for English words, markedness facilitated identification $[F(1,15)=5.92$, $p<.03$; 1181 vs $1322 \mathrm{~ms}$ for marked vs unmarked]. Moreover, whereas English marked words were significantly faster than French marked words $[F(1,15)=10.95$, $p<.005]$, French unmarked words tended to be faster than English unmarked ones $[F(1,15)=3.08, p<.08]$.

\section{Discussion}

The present study further documents the use of low-level cues by bilinguals when processing words in their two languages. Words that provide orthographic cues signaling language were identified faster than were nonmarked words. Quite interestingly, the markedness effect was present mainly in the second language of our bilingual subjects and predominantly for words presented to the right hemisphere. Indeed, for such words, markedness (of L2 words in the LVF) accelerated language identification by $141 \mathrm{~ms}$.

The above pattern of results suggests that in the present study, our bilingual participants were relying essentially upon a "perceptual" strategy in order to identify the language of words, i.e., the identification of letter patterns commonly found in only one of their languages. The finding that attentiveness to orthographic pattern was especially effective in identifying words in the second language, suggests, contrary to Favreau et al.'s (1980) finding in reading tasks, that, at least in a language recognition task, bilinguals can make use of orthographic redundancy in the second language.

Our results suggest that in the case of L2 orthographically marked words, the bilinguals were not performing a complete lexical identification of the stimulus words, but, as stated above, were relying on orthographic cues to make their decision when this possibility was afforded them. This is evidenced by the fact that identification times were considerably faster in the second, less dominant language than in the native language for orthographically marked words. Under "normal" conditions, bilingual subjects would be expected to identify words from their native, dominant language faster than those from their less proficient language (and indeed for unmarked words there was a first language advantage noted in our results). An inversion of performance in L2 relative to L1 is not generally noted for late bilinguals until they have lived for some period of time in a situation where the second language is the common vehicle of communication (Frenck-Mestre, 1993). An inversion of performance for first and second language words was not observed, moreover, for unmarked words. For these words, lexical access was most likely the means used to identify the language of the words. Indeed, even though the presentation of words was fairly rapid $(100 \mathrm{~ms})$, previous studies have clearly shown that even nonproficient bilinguals can access L2 words as early as $100 \mathrm{~ms}$ of 
presentation, even in the case of low-frequency words (Frenck-Mestre \& Prince, 1997). For more proficient bilinguals, lexical access of L2 words can be seen even under masked conditions where actual identification of the word is extremely low (Grainger \& Frenck-Mestre, 1998). Thus, lexical access could indeed have been the means of language identification for all stimulus words. However, our results support a hypothesis that this was the means of language identification essentially for unmarked words, where a "quick check" of the orthographic features of the stimulus word did not allow language identification.

Our results extend the range of phenomena for which right-hemisphere-mediated processing has been observed to include orthographic markedness. Although we found no overall visual field differences for the task of language identification, consistent with the Vaid and Frenck-Mestre (1990) results with a different bilingual sample, the higher order interaction observed in the present results indicates that the markedness manipulation, and its variation by language, was reliable only for words directed to the right-hemisphere. The finding of a right-hemisphere sensitivity in orthographic markedness further suggests to us that the markedness effect noted for L2 in the present study is predominantly a perceptual effect rather than one involving complete lexical access. It would be interesting to investigate whether comparable effects would be found in an auditory analogue of the present task.

\section{Appendix A. List of stimuli}

\begin{tabular}{|c|c|c|c|}
\hline \multicolumn{2}{|l|}{ Marked } & \multicolumn{2}{|c|}{ Unmarked } \\
\hline English & French & English & French \\
\hline \multicolumn{4}{|c|}{ List 1} \\
\hline SNOW & BRUIT & BLIND & GRIS \\
\hline WHITE & VRAI & DROP & CHENE \\
\hline AWFUL & ENCRE & APPLE & ELEVE \\
\hline OHIO & ETRE & INTO & AVANT \\
\hline YOUNG & LUIRE & COUNT & JAMBE \\
\hline WEEK & QUOI & LOVE & MORT \\
\hline KICK & VIEUX & TIME & NAIN \\
\hline EYES & OEUF & OUNCE & AUSSI \\
\hline \multicolumn{4}{|c|}{ List 2} \\
\hline GHOST & VRAC & STAIR & PLOMB \\
\hline KNEE & ARBRE & TRIBE & FRAIS \\
\hline UPPER & ENNUI & OPEN & USINE \\
\hline SLEEP & DEUIL & ABOVE & ECOLE \\
\hline YEAR & VOEU & NEVER & GAMIN \\
\hline KING & JEUDI & SOUND & HONTE \\
\hline WEIGH & SUEUR & LEMON & LOUP \\
\hline EARTH & OEUST & RULE & PONT \\
\hline
\end{tabular}

\section{References}

Carterrette, E. C., \& Jones, M. H. (1974). Informal speech: Alphabetic and phonemic texts with statistical analyses and tables. Berkeley: University of California Press.

Favreau, O., Komoda, M. K., \& Segalowitz, N. (1980). Second language reading: implications of the word superiority effect in skilled bilinguals. Canadian Journal of Psychology, 4, 370-381. 
Frenck-Mestre, C. (1993). Use of orthographic redundancy and word identification speed in bilinguals. Journal of Psycholinguistic Research, 22, 397-410.

Frenck-Mestre, C., \& Prince, P. (1997). Second language autonomy. Journal of Memory and Language, 37, 481-501.

Genesee, F., Hamers, J., Lambert, W. E., Mononen, L., Seitz, M., \& Starck, R. (1978). Language processing in bilinguals. Brain and Language, 5, 1-12.

Grainger, J., \& Beauvillain, C. (1987). Language blocking and lexical access in bilinguals. Quarterly Journal of Experimental Psychology A, 39, 295-319.

Grainger, J., \& Frenck-Mestre, C. (1998). Masked priming by translation equivalents in proficient bilinguals. Language and Cognitive Processes, 13, 601-623.

Kotik, B. (1989). Interhemispheric cooperation in speech processing in bilinguals. Unpublished doctoral dissertation, Moscow State University.

Kucera, H., \& Francis, W. N. (1967). Computational analyses of present-day American English. Providence: Brown University.

Thomas, M. S. C., \& Allport, A. (2000). Language switching costs in bilingual visual word recognition. Journal of Memory and Language, 43, 44-66.

Tresor de la Langue Francaise. (1971). Etudes statistiques sur le vocabulaire français. CNRS-TLF, Paris: Didier.

Vaid, J. (1984). Visual, phonetic, and semantic processing in early and late bilinguals. In M. Paradis, \& Y. Lebrun (Eds.), Early bilingualism and child development (pp. 175-191). Lisse: Swets \& Zeitlinger.

Vaid, J. (1987). Visual field asymmetries for rhyme and syntactic category judgments in monolinguals and fluent early and late bilinguals. Brain and Language, 30, 263-277.

Vaid, J., \& Frenck-Mestre, F. (1990). Language recognition in skilled bilinguals. Poster presented at annual meeting of the Psychonomics Society, New Orleans.

Veronis, J. (1986). Etude quantitative sur le système graphique et phonologique du Français. Cahiers de Psychologie Cognitive, 6, 501-531.

Von Studnitz, R. E., \& Green, D. W. (1997). Lexical decision and language switching. International Journal of Bilingualism, 1, 3-24. 